\title{
Technical Efficiency of Wheat Producers in North Shewa Zone of Amhara Region, Central Ethiopia
}

\author{
Tadesse Getachew ${ }^{1}$, Mengistu Ketema ${ }^{2}$, Degye Goshu ${ }^{3,4}$ \& Degnet Abebaw ${ }^{4}$ \\ ${ }^{1}$ Department of Agricultural Economics, Debre Berhan University, Ethiopia \\ ${ }^{2}$ Department of Agricultural Economics, Haramaya University, Ethiopia \\ ${ }^{3}$ Ethiopian Economic Policy Research Institute (EEPRI), Ethiopia \\ ${ }^{4}$ Ethiopian Economics Association (EEA), Ethiopia \\ Correspondence: Tadesse Getachew, Department of Agricultural Economics, Debre Berhan University, Ethiopia. \\ Tel: 251-911-777-419. E-mail: tgetachew800@gmail.com
}

Received: March 17, 2020 Accepted: May 20, 2020 Online Published: May 30, 2020

doi:10.5539/sar.v9n3p77 URL: https://doi.org/10.5539/sar.v9n3p77

\begin{abstract}
The aim of this study is to analyze technical efficiency of wheat producers and identifying the sources of inefficiency in North Shewa Zone of Amhara National Region State, Central Ethiopia. A multi-stage sampling technique was used to select sample respondent households. In the first phase, three potential wheat grower districts namely, Bassona Worrana, Siyadebrna Wayu, and Moretna Jiru were selected purposively. In the second stage, six potential kebeles (lowest administrative level), two from each of the three districts were selected. In the third phase, proportionally with population size, 374 sample households were selected using simple random sampling techniques from each of the selected kebeles. Cobb-Douglas Stochastic Frontier Production (SFP) function and inefficiency function were used to estimate the technical inefficiency level of wheat producers using a one-step maximum likelihood estimation procedure. The average productivity of wheat was found to be 32.60 quintals per hectare. Land size, fertilizer, seed, labor, and oxen power were important factors of production positively and significantly affecting wheat output. Age and education level of a farmer, off-farm income, extension contact, and credit services were found negatively and significantly affecting the technical inefficiency of wheat producing farmers. The inefficiency components contributed about $70.62 \%$ of the total deviation from the best possible production output. The average technical efficiency (TE) level of wheat producers was $72 \%$. Overall, the provision of fertilizers, credit, and extension services would make wheat producers more productive and technically efficient in the study area.
\end{abstract}

Keywords: Central Ethiopia, stochastic frontier production function, technical efficiency, wheat productivity

\section{Introduction}

Agriculture contributes about 37\% of the national Gross Domestic Product (GDP), 73\% of rural employment, and $70 \%$ of export earnings for the Ethiopian economy (FAO, 2019). The system of farming is a subsistence kind and farmers' choices are constrained by lack of inputs and technical knowledge (Central Statistical Agency (CSA, 2019)). Wheat is an important food crop in Ethiopia. It accounts for 14 percent of the total caloric intake of consumers in Ethiopia (World Bank, 2018; Minot et al., 2015). Wheat is cultivated in the highlands of Ethiopia, mainly in Oromia, Amhara, Southern Nations, Nationalities and Peoples (SNNP) and Tigray regions. In Ethiopia, wheat production by volume has increased over the past decade. In the 2018/2019 cultivation year, 4.8 million metric tons of wheat was produced and its productivity was 27.64 quintals per hectare at the national level (CSA, 2019). However, according to the Global Agriculture Information Network (GAIN, 2019) estimation, the demand for wheat for $2019 / 20$ is about 6.3 million metric tons.

Crop productivity can be increased in two ways; through improvements in technology or technical efficiency improvements (Mechri, Lys and Cachia, 2017). The former is through advanced use of technology in the production process while the latter option is through the technique of how well existing inputs are combined, given a fixed level of inputs and technology. Improving productivity using technical efficiency is a better option for developing country farmers than through adopting new technology. Because; the invention of or adoption of new technology requires capital investment. Few technical efficiency studies carried out in the Amhara region 
indicate wheat farmers are technically less efficient (Moges, 2019; Hassen, 2016; Fekadu and Bezabih, 2008). Therefore, the objective of this study is to analyze the technical efficiency of wheat producers and factors affecting technical efficiency in North Shewa Zone of Amhara National Region State, Central Ethiopia.

\section{Research Methodology}

\subsection{Description of the Study Area}

The study area, North Shewa Zone is one of the 10 zones of Amhara National Regional State of Ethiopia. This Zone is bordered on the South and West by the Oromia region, on the North part by South Wollo and Northeast by Oromia Zone and the East by Afar regions. The capital city of North Shewa Zone is Debre Berhan, $130 \mathrm{Km}$ to the North East of Addis Ababa. Geographically, the zone is located between $8^{\circ} 38^{\prime}$ to $10^{\circ} 42^{\prime} \mathrm{N}$ and $38^{\circ} 40^{\prime}$ to $40^{\circ} 03^{\prime} \mathrm{E}$ and it consists of 22 rural districts (North Shewa Zone Department of Communication Affairs, 2018).

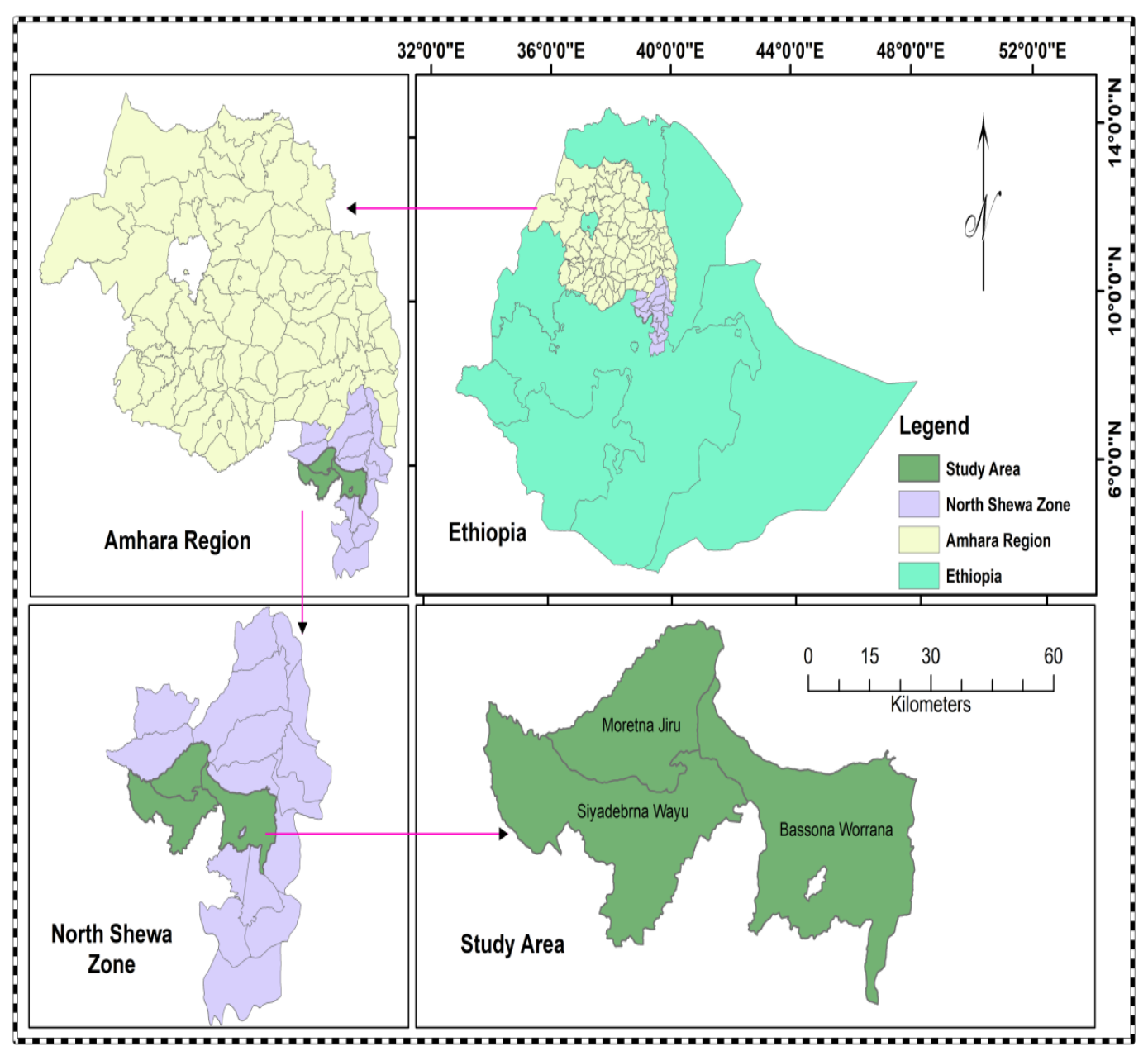

Figure 1. Map of the study area

\subsection{The Socioeconomic Characteristics of the Study Area}

According to CSA's (2007) estimation,the population size of North Shewa zone is 2.16 million, and $50.5 \%$ of which is male and $49.5 \%$ is female. The majority of the population is Amhara ethnic group (95.7\%) where the Oromo (2.14\%), and the Argobba (1.71\%); and other ethnic groups $(0.45 \%)$ also reside in the zone. The dominantly practiced religion is Orthodox Christianity. The total area of land is 15936.13 square kilometers. Mixed crop cultivation and livestock production system are the main agricultural practices in the study area.

\subsection{Data Sources and Methods of Data Collection}

Both primary and secondary data were used for this study. Primary data were collected through key informant interviews, group discussions, household surveys, and field observation. Household survey was conducted using a structured questionnaire. Trained data enumerators were used to collect the survey data. Secondary data 
(population data, socioeconomic information, etc) were collected from the respective district or Kebele (lowest administrative unit) offices. Before conducting the final survey pretest pilot survey was conducted to shape the actual survey questionnaire.

\subsection{Sampling Techniques and Sample Size}

A multi-stage sampling technique was used to select sample respondent households. In the first phase, three potential wheat grower districts namely, Bassona Worrana, Siyadebrna Wayu, and Moretna Jiru were selected purposively. In the second stage, six potential kebeles, two from each of the three districts were selected. In the third phase, proportionally with population size, sample households were selected using simple random sampling techniques from each of the selected kebeles. To determine the minimum sample size the formula developed by Yamane (1967) was employed,

$$
n=\frac{N}{1+N\left(e^{2}\right)}
$$

Where $\mathrm{n}$ is the sample size, $\mathrm{N}$ is the population size, and e is the level of precision. At a $95 \%$ confidence levels the level of precision (error), e $=0.05$ is assumed. Based on equation (1) a total of 374 sample households were selected randomly proportional to the total population size from the six potential wheat grower Kebeles.

\subsection{Methods of Data Analysis}

Both descriptive statistics and econometric methods are used for data analysis. Descriptive statistics (minimum, maximum, mean, etc) were used to describe the variables used in each model. Parametric Stochastic Frontier Production (SFP) econometric model developed by Aigner, Lovell, and Schmidt (1977) was used to analyze production inefficiency. The relationship between the wheat output $\left(\mathrm{Y}_{\mathrm{i}}\right)$ and the inputs used $\left(\mathrm{X}_{\mathrm{i}}\right)$ is represented through the production function $\mathrm{f}($.) as follows,

$$
\ln Y_{i}=\beta_{0}+\sum_{n=1}^{N} \beta_{n} \ln X_{n i}+\boldsymbol{E}_{i}\left(V_{i}-U_{i}\right)
$$

Where, ln denotes the natural logarithm, $\mathrm{Y}_{\mathrm{i}}$ is the wheat output of a given farmer $i ; \beta$ is a vector of parameters to be estimated; $\mathrm{X}_{\mathrm{i}}$ is the vector of input quantities supposed to affect production function; $\varepsilon_{i}$ is error term equals to $\left(V_{i}-U_{i}\right) ; V_{i}$ represents the independently and identically distributed $\mathrm{N}\left(0 ; \sigma^{2}\right)$ random errors (statistical noise). It is randomly distributed in the production process that cannot be influenced by the farmer and is independent of $U_{i}$; $U_{i}$ represents non-negative random variables associated with technical inefficiency in production, independently and identically distributed as half-normal with mean $\mu, \mathrm{u} \sim\left(\mathrm{N}^{+}\left(\mu, \sigma_{u}^{2}\right)\right)$. As Battese and Coelli (1988) indicated the maximum likelihood (ML) estimation of Eq. (2) yields estimators for $\beta$ and $\gamma$;

$$
\begin{gathered}
\sigma^{2}=\sigma_{u}^{2}+\sigma_{v}^{2} \\
\gamma=\sigma_{u}^{2} / \sigma_{u}^{2}+\sigma_{V}^{2}
\end{gathered}
$$

Where; the $\gamma$ parameter has a value between 0 and 1. A zero value of $\gamma$ indicates that the deviations from the frontier are due entirely to noise, while a value of 1 would indicate that all deviations are due to technical inefficiency. $\sigma^{2}{ }_{u}$ is the variance parameter that denotes deviation from the frontier due to inefficiency; $\sigma^{2}{ }_{V^{-}}$is the variance parameter that denotes deviation from the frontier due to noise. $\sigma^{2}$-is the variance parameter that denotes the total deviation from the frontier.

The dependent variable in SFP model is wheat output and the hypothesized independent variables are described in Table 1.

Table 1. Description of hypothesized independent variables in the SFP model

\begin{tabular}{llll}
\hline Variable Notation & Variable explanation & Unit of Measurement & Expected sign \\
\hline Area & Area allocated to wheat crop & hectare & + \\
& Nitrogen, Phosphors, Sulfur, Zink and Boron & & \\
NPSZnB & complex fertilizer used for wheat production & quintals & + \\
Urea & Urea used for wheat production & quintals & + \\
Seed & Wheat seed sowed & Kilograms & + \\
Labor & Labor used for wheat production & Man-days & + \\
Oxen labor & Oxen labor used for wheat production & Oxen-days & + \\
\hline
\end{tabular}

Source: Reviewed empirical literature 
The technical efficiency of production $\left(\mathrm{TE}_{\mathrm{i}}\right)$ of the $\mathrm{i}^{\text {th }}$ farmer given the levels of inputs is defined by equation 5 ,

$$
T E_{i}=Y_{i} / f\left(X_{i} ; \beta\right) \exp \left(V_{i}\right)=\exp \left(-U_{i}\right)
$$

The technical efficiency of a farmer is between 0 and 1 and is inversely related to the level of the technical inefficiency effect. Technical inefficiency effect $\left(U_{i}\right)$ with mean $\mu_{\mathrm{i}}$ is defined as,

$$
U_{i}=\alpha_{0}+\alpha_{1} L_{i}+\ldots+\alpha_{n} L_{n}+z_{i}
$$

Where, $\mathrm{L}_{\mathrm{i}}$ is the characteristics of the farmer (age, gender, educational level, etc). The $\alpha_{0}$ and $\alpha_{\mathrm{i}}$ coefficients are unknown parameters to be estimated along with the variance parameters $\sigma^{2}$ and $\gamma$, and $Z_{i}$ is the error term.

The technical inefficiency scores are taken as the dependent variable in the inefficiency model. Independent variables proposed to affect the inefficiency of wheat producers and their description is indicated in Table 2 . The SFP and inefficiency functions (equations 2 and 6) can be estimated in one or a two-step procedure. As indicated in Wang and Schmidt's (2002) two-step estimation procedures results in biased coefficients. Hence this study used a one-step estimation procedure.

Table 2. Hypothesized variables included in the inefficiency model

\begin{tabular}{llll}
\hline Variable Notation & Variable explanation & Unit of Measurement & Expected sign \\
\hline Age & Age of household head & Years & + \\
Gender & Sex of household head & Dummy male=1 & - \\
Education & The education level of household head & Years & - \\
Distance & Distance from home to the nearest market & Kilometers & + \\
Credit & Access to credit services & Dummy, Yes=1 & - \\
Dependency & Dependency ratio of household & Number & + \\
Off-farm income & Availability of off-farm income & Dummy yes=1 & + -/ \\
Extension service & Frequency of extension service & Number & - \\
Livestock & Total available livestock asset & TLU & - \\
\hline
\end{tabular}

Source: Reviewed empirical literature

\section{Results and Discussion}

\subsection{Descriptive Results}

Mean, minimum, and maximum wheat yield in the 2018/2019 cultivation year from the sampled households was $32.60,12$, and 64 quintals per hectare, respectively (Table 3 ).

Table 3. Descriptive results of variables used in the SFP model

\begin{tabular}{lllcll}
\hline Variable & Obs. & Mean & Std.Dev & Min & Max \\
\hline Wheat yield (q/ha) & 374 & 32.60 & 11.24 & 12 & 64.00 \\
Area (ha) & 374 & 0.82 & 0.461 & 0.125 & 2.50 \\
Urea (q/ha) & 374 & 2.64 & 0.70 & 0.53 & 5.50 \\
NPSZnB (q / ha) & 374 & 3.03 & 1.05 & 0.90 & 6.80 \\
Seed (kg / ha) & 374 & 195 & 70.21 & 50 & 620 \\
Labor (man days / ha) & 374 & 54 & 18.50 & 9.60 & 108 \\
Oxen labor(oxen days /ha) & 374 & 55 & 21.16 & 6.40 & 100 \\
\hline
\end{tabular}

Source: own computation (2018/2019)

The average amounts of NPSZnB and urea fertilizers applied were 3.03 and 2.64 quintals per hectare, respectively. The result did not agree with the Amhara National Regional State agriculture bureau recommendation for the study area (ANRS, 2019). The average oxen and human labor used for wheat production were 55 and 54, respectively. Oxen labor range from 6.4 to 100 per hectare and that of human labor varies from 9.60 to 108 man-days per hectare. The large variation in oxen and human labor input variables was because of the fact that some farmers were using modern mechanized farming systems. 
Table 4. Descriptive results of variables used in the inefficiency model

\begin{tabular}{lcllllll}
\hline Variable & Obs & Mean & Std. Dev & Min & Max & Frequency & Percentage \\
\hline Age & 374 & 37 & 17.10 & 18 & 82 & & \\
Education status & 374 & 4.43 & 4.54 & 0 & 13 & & \\
Dependency ratio & 374 & 0.76 & 0.819 & 0 & 6.20 & & \\
Distance to market & 374 & 7.81 & 4.54 & 1 & 20 & & \\
Extension service & 374 & 5.22 & 3.54 & 0 & 12 & & \\
Livestock & 374 & 5.82 & 2.29 & 0 & 12.44 & & \\
Gender & Male & & & & & 290 & 77.54 \\
& Female & & & & & 84 & 22.46 \\
Off-farm income & No & & & & & 252 & 67.38 \\
& Yes & & & & & 122 & 32.62 \\
Access to credit & No & & & & & 196 & 52.40 \\
& Yes & & & & & 178 & 47.60 \\
\hline
\end{tabular}

Source: Own computation (2018/2019)

Farmers using modern mechanization (tractor plowing and combine harvesters) used lesser oxen and human labors than non-mechanized farmers. The average age of sampled household heads is 37 years, ranging from 18 to 82 years. The result also indicates 32.62 percent of sample households had off-farm income sources (Table 4). The major off-farm income sources in the study area were petty trades, renting a house, and daily labor work. The major institutions providing credit service in the study area were Amhara Credit and Saving Institution (ACSI) and farmer's cooperatives.

\subsection{Econometric Results}

\subsubsection{Hypotheses Test}

Following the recommendation of Kumbhakar, Wang, and Horncastle (2015), the fitness of parametric models (model selection, inefficiency effect test and determinants of coefficients) were tested using the generalized likelihood ratio (LR) test as indicated in (Table 5). Before testing the fitness of the models the data was checked for multicollinearity and heteroscedasticity problems and there were no serious problems found in the data.

$$
L R=-2\left[\operatorname{Ir}\left(H_{0}\right)-\operatorname{Ir}\left(H_{1}\right)\right]
$$

Where $\mathrm{H}_{0}$ represents the log-likelihood value of the null hypothesis and $\mathrm{H}_{1}$ is the log-likelihood value of the alternative hypothesis. Taking the number of restrictions equals the degree of freedom, the calculated LR value is compared with the critical values of chi-square ( $\chi 2)$ reported in Kodde and Palm (1986). If the calculated LR value is less than the critical value we cannot reject the null hypothesis.

Table 5. Generalized likelihood Ratio Tests

\begin{tabular}{|c|c|c|c|c|}
\hline Hypothesis & $\mathrm{df}$ & $\begin{array}{l}\text { Calculated } \\
\text { LR-value }\end{array}$ & $\begin{array}{l}\text { Critical value } \\
\chi^{2}(0.05)\end{array}$ & Decision \\
\hline 1. $\mathrm{H}_{\mathrm{o}}:$ No inefficiency component $(\gamma=0)$ & 1 & 128 & 3.84 & Reject \\
\hline $\begin{array}{l}\text { 2. } \mathrm{H}_{\mathrm{o}} \text { : Production function is SFP Cobb-Douglas } \\
\qquad\left(\beta_{7}=\beta_{8}=\ldots=\mathrm{B}_{27}=0\right)\end{array}$ & 20 & 26 & 31.41 & Accept \\
\hline 3. $\mathrm{H}_{0}: \alpha_{1}=\alpha_{2} \ldots=\alpha_{9}=0$ & 9 & 128 & 16.91 & Reject \\
\hline
\end{tabular}

Source: Own computation (2018/2019)

The first hypothesis was done to check the presence of inefficiency in the respondent's production function. The test was made by comparing the ordinary least squares (OLS) and SPF models to fit the data. This was conducted using the likelihood ratio formula displayed in equation (7), the test result indicates the calculated LR value (128) exceeds the critical value (3.84) at 1 degree of freedom and 5\% significant level so that the null hypothesis should be rejected. Meaning that the hypothesis assumed no technical inefficiency in the data should be rejected. This implies that the SPF function is an appropriate functional form for the data.

The second hypothesis test was to check the appropriateness of the Cobb-Douglas functional form in preference to translog model. The computed LR statistic value is 26 which is less than the critical value (31.41) at 20 
degrees of freedom and 5\% probability level. Thus the null hypothesis is accepted indicating the Cobb-Douglas functional form better explain the data than the translog functional form. Thus the coefficients of the interaction terms and the square specifications of the input variables under the translog specifications were not different from zero. The third hypothesis test is about the null hypothesis stating the independent variables related to the technical inefficiency effect are zero against the alternative hypothesis of these variables related to the technical inefficiency effects are (at least one of them) different from zero. The test result indicates the calculated LR value is (128) exceeds the critical value of 16.91 at 20 degrees of freedom and 5\% significance level indicating that the null hypothesis should be rejected. In other words, the test result confirmed the technical inefficiency difference between respondents was attributed to the inefficiency variables.

\subsubsection{Parameter Estimation of the SFP Model}

Cross-sectional data sets fitted with the SFP model and the inefficiency model were estimated in a one-step procedure using STATA version 15. The result of the ML estimates (Table 6) indicates, except for NPSZnB fertilizer, all other input variables affected wheat production positively and significantly.

Table 6. ML Estimates of Cobb-Douglas SFP function

\begin{tabular}{llll}
\hline Input variable & Coefficient & Std.Err & $\mathrm{Z}$ \\
\hline lnArea & $0.61^{* * *}$ & 0.062 & 9.84 \\
lnUrea & $0.08^{*}$ & 0.044 & 1.73 \\
$\ln N$ PSZnB & 0.012 & 0.034 & 0.35 \\
lnSeed & $0.22^{* * *}$ & 0.04 & 5.59 \\
lnLabor & $0.07^{*}$ & 0.036 & 1.91 \\
lnOxenLabor & $0.12^{* * *}$ & 0.035 & 3.42 \\
Constant & $1.79^{* * *}$ & 0.27 & 6.64 \\
Gamma $(\gamma)$ & 0.7062 & & \\
Lambda $(\lambda)$ & $1.55^{* * *}$ & & \\
Log-likelihood & 46.25 & & \\
Mean TE & $72 \%$ & & \\
\hline
\end{tabular}

Source: Own computation from a survey (2018/2019)

Note: *,*** represents $10 \%$ and $1 \%$ significant probability level, respectively.

Keeping all other input variables constant, a $1 \%$ increase in the area of land allocated to wheat crop would raise the wheat output by $0.61 \%$. The result is consistent with the findings of Moges (2019); Milkessa, Endrias, and Fikadu (2019) and Hassen (2016). Next to land, the amount of seed has the highest contribution for wheat output increment. Increasing the quantity of seed by $1 \%$, ceteris paribus would increase wheat yield by $0.22 \%$. The result is in line with the findings of Kaleb and Workneh (2016) and Solomon (2014). Similar to our prior expectation, Urea fertilizer affected yield positively and significantly at a $10 \%$ level. The finding is in line with the theory fertilizer supplements the missed soil nutrients to increase productivity. The result is supported by several empirical works done in Ethiopia (Milkessa et al., 2019; Moges, 2019; Hassen, 2016 and Wudineh and Endris, 2016). The application of NPSZnB fertilizer affected wheat output positively but it was not significant. The probable reason may be the wrong agronomic management practice of farmers to NPSZnB fertilizer.

Both human labor and oxen power were found positively and significantly affected wheat yield. This is because both of them are the determining factors of production in the study area. Farmers used oxen labor for land preparation, sowing, and threshing wheat crop. The result met our prior expectations and agrees with the findings of Hassen (2016) and Asefa (2011). The summation of individual input elasticity is 1.112 (increasing return to scale of production). This means a unit increment of all inputs proportionally would increase wheat output by more than a unit amount. The result agrees with the findings of Milkessa et al. (2019), Hassen (2016), Solomon (2014), and Fekadu and Bezabih (2008).

\subsubsection{Technical Efficiency Scores}

The mean technical efficiency (TE) of sample farmers was $72 \%$ (Table 6). That is to say an average wheat producer in the sample was performing below $28 \%$ of the maximum potential output. In other words, on average it could be possible to raise wheat output by about $28 \%$ without employing more inputs. 


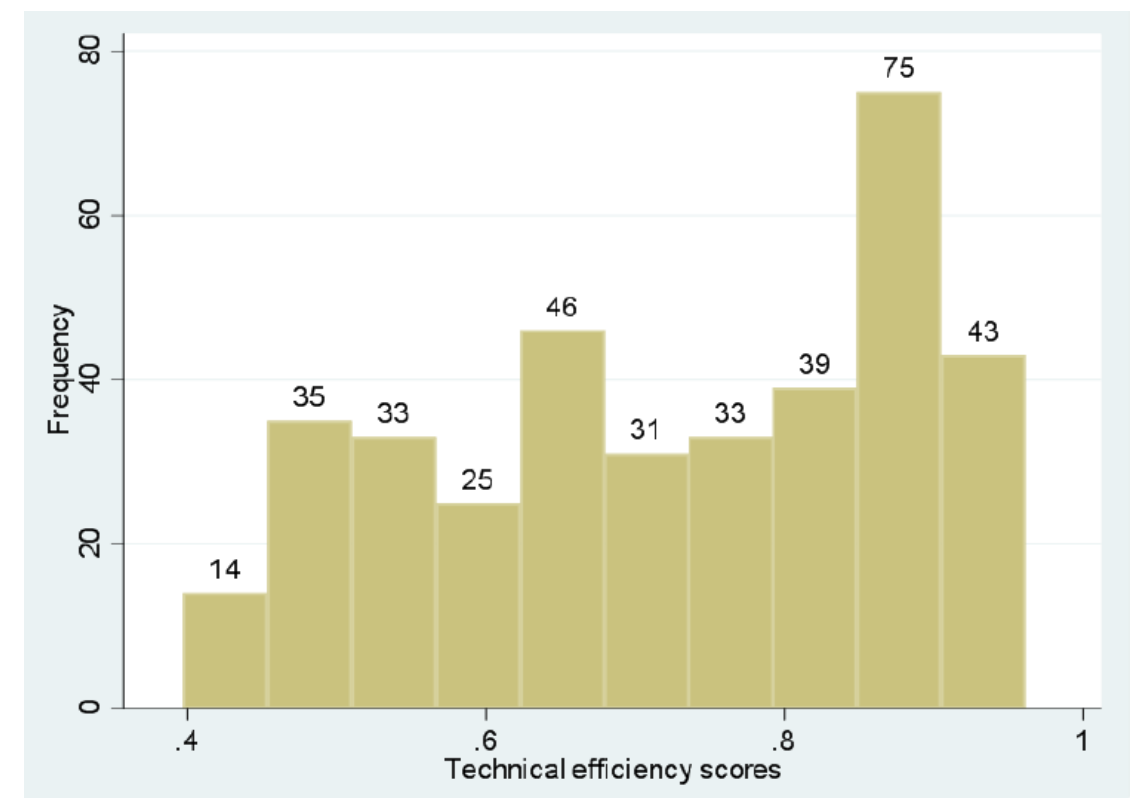

Figure 2. Technical efficiency distribution

Source: Own computation (2018/2019)

The minimum TE was $40 \%$, meaning that the least performing farmer in the sample was operating $60 \%$ below the maximum potential output. The maximum TE is $96 \%$. That is, the best performer farmer was only $4 \%$ below the frontier possibility curve. The frequency distribution map indicates about 58\% of wheat producers' TE was below $80 \%$ (Figure 2).

\subsubsection{Determinants of Technical Inefficiency of Wheat Producers}

As indicated in (Table 7) age, education, availability of off-farm income, extension service, and availability of credit were found significantly affecting the technical inefficiency level of wheat producers in the study area.

Age of household head: Different from prior expectation age of household head impacted technical inefficiency negatively and significantly at a 5\% probability level. This is because, as the age of the farmer increases his/her experience of crop production also increases. Experienced farmers used inputs more efficiently than their younger counterparts. The marginal effects of age on technical efficiency imply an additional 1 year age of a farmer would increase his /her technical efficiency by $0.1 \%$ in the study area. A similar argument was made by Moges (2019), Milkessa et al. (2019), Hassen (2016), and Wudineh and Enderias (2016).

Table 7. Determinants of technical inefficiency of wheat producers

\begin{tabular}{lllll}
\hline Inefficiency Variable & Coef & Std.Err & $\mathrm{Z}$ & Marginal effect (dy/dx) \\
\hline Age & $-0.002^{* *}$ & 0.001 & -2.04 & 0.001 \\
Gender & -0.017 & 0.041 & -0.42 & 0.015 \\
Education status & $-0.023^{* * *}$ & 0.006 & -3.80 & 0.010 \\
Dependency ratio & 0.014 & 0.022 & 0.64 & -0.010 \\
Off-farm income & $-0.062^{*}$ & 0.036 & -1.72 & 0.034 \\
Livestock & -0.012 & 0.007 & -1.63 & 0.006 \\
Distance to market & -0.003 & 0.005 & -0.62 & 0.000 \\
Extension service & $-0.042^{* * *}$ & 0.009 & -4.78 & 0.018 \\
Access to credit & $-0.19^{* * *}$ & 0.047 & -3.99 & 0.09 \\
Constant & $0.88^{* * *}$ & 0.095 & 9.26 & \\
\hline
\end{tabular}

Source: Own computation (2018/19)

Note: *,**,**, represents $10 \%, 5 \%$ and $1 \%$ significant probability level, respectively.

\section{Education level of Household Head}

The technical inefficiency of a farmer was influenced by education level negatively at $1 \%$ significant. This is 
because as the education level of a farmer increases, he/she will be able to perceive, interpret, and adopt modern farm technologies to improve productivity and technical efficiency level. The marginal effect of education on technical efficiency indicates an additional year of education on average would increase the technical efficiency level of a farmer by $1 \%$ (Table 7). The result is supported by the findings of Moges (2019), Milkessa et al. (2019), and Wudneh and Endris (2016).

Off-farm Income/Dummy variable/: Off-farm income is an additional income made by households through engagement in a certain work besides farming. The result of this study indicates off-farm income affected technical inefficiency negatively at a $10 \%$ significant level. This is because households who have off-farm income would have better capability to purchase farm inputs, additional food, and health securities than those with no off-farm income. The marginal effect of off-farm income on the technical efficiency of sample farmers with off-farm income sources was 3.4\% higher than the technical efficiency of farmers without an off-farm income source. Our finding disagrees with the findings of Hassen (2016) but agrees with Milkessa et al. (2019) and Asefa (2011).

\section{Extension Service}

Extension service is used to transform and strengthen the adoption of modern technology. Similar to our prior expectation the result of this study indicate the frequency of extension contact to wheat producers affected technical inefficiency level negatively at a $1 \%$ significant level. The result is in line with the works of Milkessa et al.(2019) and Beneberu et al. (2018).The marginal effect of extension service indicates a unit increase in the number of extension contact between an agent and a farmer in the production year would increase the technical efficiency of a farmer by $1.8 \%$ (Table 7).

\section{Access to Credit /A dummy variable/:}

As expected, credit access negatively influenced the household`s production inefficiency. The marginal effect of credit on efficiency indicates households who have access to credit services were $9 \%$ more efficient than those households that do not have access to credit. This is because credit access solves the cash constraints of poor farmers. Households that have access to credit can secure inputs on time to become a more efficient producer. Our finding agrees with the findings of Moges (2019) and Assefa (2011).

\section{Conclusion and Recommendations}

The objective of this study was to analyze the technical efficiency and sources of inefficiency of wheat producers in North Shewa Zone of Amhara National Region State, Central Ethiopia. The SFP function and inefficiency functions were used to analyze the production function and the technical inefficiency level of wheat producers in a one-step ML estimation procedure. The average wheat yield was 32.60 quintals per hectare in the study area in the 2018/2019 cultivation year. Land allocated to wheat, fertilizer, seed, labor, and oxen labors positively and significantly affected wheat production in the study area. Age and education level of a farmer, availability of off-farm income, extension service, and availability of credit services negatively and significantly affected the technical inefficiency of wheat producers. The inefficiency components $(\gamma$-value) contributed $70.62 \%$ of the deviation from the production frontier. The average technical efficiency score of wheat producers was $72 \%$, thus there is an opportunity to raise wheat output by $28 \%$ with the available technology in the study area. The return to the scale of production was 1.112 . Increasing all inputs proportionally by one percent would increase wheat output more than one percent. In other words, it is possible to increase wheat yield by increasing input quantities in the study area. Providing farmers with appropriate fertilizers, credit, and extension services on time would make wheat producers productive and technically efficient. Policies and strategies which can raise the education level of farmers, extension service, credit, and off-farm income source make farmers more productive and efficient wheat producers in the study area.

\section{Acknowledgments}

The authors would like to thank wheat-producing farmers and agricultural development extension agents of Bassona Worrana, Siyadebrna Wayu, and Moretna Jiru districts who collaborated with us during the data collection. We also extend our thankfulness to the Ethiopian Ministry of Science and Higher Education who funded this research work.

\section{References}

Aigner, D., Lovell, K., \& Schmidt, P. (1977). Formulation and estimation of stochastic frontier production function models. Journal of Econometrics, 6(1), 21-37. https://doi.org/10.1016/0304-4076(77)90052-5

ANRS (Amhara National Regional State). (2019). Agriculture Bureau, Wheat development packaging. 
Asefa, S. (2011). Analyzing technical efficiency of crop-producing smallholder farmers in the Tigray region, Ethiopia. Stochastic frontier analysis. MPRA Paper No. 40461. Retrieved from https://doi.org/mpra.ub.uni-muenchen.de/40461/

Battese, G., and Coelli, T.(1988). Prediction of firm-level technical efficiencies with a generalize frontier production function and panel data. Journal of Econometrics 38(1988) 387-399, North-Holland. https://doi.org/10.1016/0304-4076(88)90053-X

Beneberu, T., Belaineh, L., Jema, H., \& Girma, T. (2018). Farm level efficiency of crop production in the central highlands of Ethiopia. American Journal of Rural Development, 6(2). https://doi.org/10.12691/ajrd-6-2-4

CSA (Central Statistical Agency). (2019). The Federal democratic republic of ethiopia, agricultural sample survey, Statistical Bulletin. Addis Ababa, Ethiopia.

CSA (Central Statistical Agency). (2007). The Federal Democratic Republic of Ethiopia, Population and housing census of Ethiopia. Addis Ababa, Ethiopia.

FAO (2019). The National gender profile of agriculture and rural livelihoods, Ethiopia. Country Gender Assessment series, Addis Ababa. 84 pp. License: CC BY-NC-SA 3.0 IGO.

Fekadu, G. and Bezabih, E. (2008). Analysis of technical efficiency of wheat production: A case study in Machakel Woreda, Ethiopia. Eth. J. of Agric. Econ, 7(2).

GAIN (Global Agricultural Information Network). (2019).

Hassen, B. (2016). Technical efficiency measurement and their differential in wheat production. The Case of smallholder farmers in South Wollo. International Journal of Economics, Business and Finance, 4(1). https://doi.org/ijebf.com

Kaleb, K., \& Workneh, N. (2016). Analysis of levels and determinants of technical efficiency of wheat-producing farmers in Ethiopia. African Journal of Agricultural Research, 11(36), 3391-340. https://doi.org/10.5897/AJAR2016.11310

Kodde, D., \& Palm, C. (1986). Wald criteria for jointly testing equality and inequality restrictions. Econometrica, 54, 1243-8. https://doi.org/10.2307/1912331

Kumbhakar, S., Wang, H., \& Horncastle, A. (2015). A Practitioner's guide to stochastic frontier analysis using Stata, Cambridge Books, Cambridge University Press. https://doi.org/10.1017/CBO9781139342070

Mechri, A., Lys, P., \& Cachia, F. (2017). Productivity and efficiency measurement in agriculture, literature review and gaps analysis. technical report series GO-19-2017.

Milkessa, A., Endrias, G., \& Fikadu, M. (2019). Economic efficiency of smallholder farmers in wheat production: The Case of Abuna Gindeberet District, Western Ethiopia. Review of Agricultural and Applied Economics Acta Oeconomica et Informatica, XXII, 65-75. https://doi.org/10.15414/raae.2019.22.01.65-75

Minot, N., Warner, J., Solomon, L., Leulsegged, K., Abate, G., \& Rashid, S. (2015). Wheat in Ethiopia: Production, marketing, and consumption. prepared for the Ethiopian agricultural transformation agency.

Moges, D. (2019). Analysis of technical efficiency of smallholder wheat growing farmers of Jamma district, Ethiopia. Agric \& Food Secur, 8(1). https://doi.org/10.1186/s40066-018-0250-9

North Shewa Zone Department of Communication Affairs. (2018). Annual Bulletin, North Shewa Zone Amhara National Regional State. Debre Berhan.

Solomon, W. (2014). Technical efficiency of major crops in ethiopia: Stochastic frontier model. Academia Journal of Agricultural Research, 2(6), 147-153. http://doi.org/10.15413/ajar.2014.0109

Wang, H., \& Schmidt, P. (2002). One-Step and Two-Step estimation of the effects of exogenous variables on technical efficiency levels. Journal of Productivity Analysis, 18, 129-144. https://doi.org/10.1023/A:1016565719882

World Bank. (2018). Cereal market performance in, policy implications for improving investments in maize and wheat value chains, Ethiopia.

Wudineh, G., \& Endrias, G. (2016).Technical efficiency of smallholder wheat farmers: The Case of Welmera District, Central Oromia, Ethiopia. Journal of Development and Agricultural Economics, 8(2), 39-51. https://doi.org/10.5897/JDAE2015.0660

Yamane, T. (1967). Statistics: An Introductory analysis, (2nd ed), New York: Harper and Row. 


\section{Copyrights}

Copyright for this article is retained by the author(s), with first publication rights granted to the journal.

This is an open-access article distributed under the terms and conditions of the Creative Commons Attribution license (http://creativecommons.org/licenses/by/3.0/). 